\title{
PTEN gene mutations correlate to poor prognosis in glioma patients: a meta-analysis
}

\author{
This article was published in the following Dove Press journal: \\ OncoTargets and Therapy \\ 13 June 2016 \\ Number of times this article has been viewed
}

\author{
Feng $\operatorname{Han}^{1, *}$ \\ Rong $\mathrm{Hu}^{2, *}$ \\ Hua Yang' \\ Jian Liu' \\ Jianmei Sui' \\ Xin Xiang' \\ Fan Wang' \\ Liangzhao Chu' \\ Shibin Song'
}

'Department of Neurosurgery, Affiliated Hospital of Guizhou Medical University, ${ }^{2}$ Department of Histology and Embryology, College of Basic Medical Sciences, Guizhou Medical University, Guiyang, Guizhou, People's Republic of China

*These authors contributed equally to this work
Correspondence: Hua Yang; Jian Liu Department of Neurosurgery, Affiliated Hospital of Guizhou Medical University, No 28, Guiyi Street, Yunyan District, Guiyang, 550004, Guizhou Province, People's Republic of China

Tel +86 85I 13985402206 ;

+86 85I 86770182

Email yhmed@163.com;

568189388@qq.com
Background: We conducted this meta-analysis based on eligible trials to investigate the relationship between phosphatase and tensin homolog (PTEN) genetic mutation and glioma patients' survival.

Methods: PubMed, Web of Science, and EMBASE were searched for eligible studies regarding the relationship between PTEN genetic mutation and glioma patients' survival. The primary outcome was the overall survival of glioma patient with or without PTEN genetic mutation, and second outcome was prognostic factors for the survival of glioma patient. A fixed-effects or random-effects model was used to pool the estimates according to the heterogeneity among the included studies.

Results: Nine cohort studies, involving 1,173 patients, were included in this meta-analysis. Pooled results suggested that glioma patients with PTEN genetic mutation had a significant shorter overall survival than those without PTEN genetic mutation (hazard ratio $[\mathrm{HR}]=2.23$, 95\% confidence interval $[\mathrm{CI}]: 1.35,3.67 ; P=0.002)$. Furthermore, subgroup analysis indicated that this association was only observed in American patients (HR $=2.19,95 \%$ CI: 1.23, 3.89; $P=0.008$ ), but not in Chinese patients (HR $=1.44,95 \% \mathrm{CI}: 0.29,7.26 ; P=0.657)$. Histopathological grade $(\mathrm{HR}=1.42,95 \% \mathrm{CI}: 0.07,28.41 ; P=0.818)$, age $(\mathrm{HR}=0.94,95 \% \mathrm{CI}: 0.43,2.04$; $P=0.877)$, and sex ( $\mathrm{HR}=1.28,95 \% \mathrm{CI}: 0.55,2.98 ; P=0.564)$ were not significant prognostic factors for the survival of patients with glioma.

Conclusion: Current evidence indicates that PTEN genetic mutation is associated with poor prognosis in glioma patients. However, this finding is derived from data in observational studies, potentially subject to selection bias, and hence well conducted, high-quality randomized controlled trials are warranted.

Keywords: glioma, PTEN genetic mutation, meta-analysis

\section{Introduction}

Glioma is the most common neoplasm of the central nervous system, accounting for $\sim 40 \%-50 \%$ of brain tumors. ${ }^{1}$ In $2008,237,913$ individuals were diagnosed with a primary malignant brain tumor worldwide. ${ }^{2}$ The overall survival (OS) rates of highgrade glioma at 1 - and 5 -year were $40 \%$ and $<10 \%$, respectively. ${ }^{3}$ The high mortality rate of gliomas is attributable to their invasiveness and high recurrence rate. ${ }^{4,5}$ Despite advances in diagnostics and treatment, such as modern diagnostic procedures, novel surgical techniques, and subsequent radiochemotherapy, the prognosis of patients suffered from high-grade glioma remains dismal. ${ }^{6}$ As a result of this, great attention has been recently paid to specific tumor-related molecular markers, as complement to traditional pathology-based diagnostic and prognostic markers, and as potential individualized therapeutic targets. ${ }^{7}$ 
Phosphatase and tensin homolog (PTEN), located on chromosome $10 \mathrm{q} 23.3$, is one of the most commonly lost or downregulated genes implicated in brain, breast cancer, and prostate tumors. ${ }^{8}$ PTEN is a tumor suppressor gene, playing important roles in the regulation of cell proliferation, adhesion and invasion, apoptosis, and DNA damage repair. ${ }^{9-11}$ The loss of PTEN expression has been indicated to be an early event in glioma, with mutations occurring in between $5 \%$ and $40 \%$ of glioma cases. ${ }^{12-14}$ Previous studies indicated that tissue growth and cell number are influenced by Pten. ${ }^{15,16}$ Moreover, Pten has independently been shown to play roles in both neurogenesis and gliogenesis. ${ }^{17,18} \mathrm{In}$ the nervous system, deletion of Pten in neural progenitor cells during embryogenesis disrupts migration and proper formation of the laminar structure of the brain. And Pten loss results in disrupted regulation of cell size or cell number in the brain and underscores the importance of Pten in normal central nervous system development and maintenance..$^{19,20}$

It has been reported that the mutations of PTEN have been involved with malignant progression of glioma: ${ }^{21,22}$ thus, they are correlated with a shorter OS in glioma. However, the prognostic significance of PTEN in glioma is still a matter of debate. Some studies have suggested that PTEN gene mutations in glioma are associated with poor survival, ${ }^{23,24}$ whereas other studies have reported that PTEN gene mutations have no correlation with survival. ${ }^{25,26}$ Therefore, we conducted this meta-analysis based on available studies to investigate the relationship between PTEN gene mutation and glioma patients' survival.

\section{Materials and methods}

\section{Search strategy and selection criteria}

Literature searches of PubMed, Web of Science, and EMBASE database (up to September 2, 2015) were performed to identify studies that investigated the relationship of PTEN gene mutational status in glioma patients and its association with patients' survival. The following search strategy was used: ("glioma"[MeSH Terms] OR "glioma"[All Fields]) AND (PTEN[All Fields] OR (("phosphoric monoester hydrolases"[MeSH Terms] OR ("phosphoric"[All Fields] AND “monoester"[All Fields] AND "hydrolases"[All Fields]) OR "phosphoric monoester hydrolases"[All Fields] OR "phosphatase"[All Fields]) AND ("tensins"[Supplementary Concept] OR “tensins"[All Fields] OR "tensin"[All Fields]) AND homolog[All Fields])). There was no limitation on language and year of publication. In addition, the reference lists of the identified studies were manually searched to include other potentially eligible trials. This process was performed iteratively until no additional studies could be found.

Studies meeting the following inclusion criteria were included: 1) study design: case-control or cohort studies; 2) study population: adult patients with a histological or pathological diagnosis of glioma; and 3) outcome measure: provided sufficient information on the genotype frequencies of PTEN genetic mutation and available data on the association between PTEN genetic mutation and patients' survival.

\section{Data extraction and quality assessment}

Two authors (HY and FH) independently extracted the following information from the selected studies: first author, year of publication, number of patients in each group, patients' characteristics, study design, duration of follow-up, genotyping method, genotype frequencies, and OS. A standardized Excel file was established to extract the data. All the entered data were checked by another author $(\mathrm{RH})$. Disagreements among them were resolved by discussion and consensus. When the same trial appeared in different publications, we only chose the most information or latest article to avoid duplication of information.

The methodological quality of the trials included in this meta-analysis was assessed by the modified Newcastle-Ottawa Scale. ${ }^{27}$ The scale consists of three items describing subject selection ( $0-4$ points), comparability of subject ( $0-2$ points), and outcome ( $0-3$ points). The full score of Newcastle-Ottawa Scale was 9 points. And articles with a total score more than 5 points were considered as high quality. ${ }^{27}$

\section{Statistical analysis}

We investigated the relationship between PTEN genetic mutation and the prognosis of patients with glioma based on the data extracted from the studies included in this metaanalysis. For the time-to-event variables (ie, OS), they were expressed as hazard ratio (HR) with $95 \%$ confidence intervals (CIs) for each study. Before the data were aggregated, Cochran's Q chi-square test and $I$ analysis were conducted to assess the presence of heterogeneity among the included studies. A $P$-value $<0.1$ or $P^{2}>50 \%$ indicated significant heterogeneity. ${ }^{28} \mathrm{~A}$ random-effects model was used to pool the estimates when the heterogeneity was present; ${ }^{29}$ otherwise, a fixed-effects model was used..$^{30}$ In some studies, Kaplan-Meier curves were provided instead of HR and 95\% CI; in these cases, we used the method described by Tierney to estimate the HR and $95 \%$ CI from the KaplanMeier curves. ${ }^{31}$ Publication bias was evaluated using the test of Begg $^{32}$ and Egger. ${ }^{33} \mathrm{~A} P$-value $<0.05$ was judged as 
statistically significant, except where otherwise specified. All analyses were performed with STATA, Version 12.0 (Stata Corporation, College Station, TX, USA).

\section{Results}

\section{Identification of eligible studies}

The initial search yielded 746 relevant records from PubMed, Web of Science, and EMBASE. Four hundred and fifty-two records were excluded for duplicates, and 277 records were excluded based on title/abstracts for various reasons. Of the 277 records, 194 were animal experiments or unrelated with our topics, 43 were reviews, 21 were case reports, and $19 \mathrm{did}$ not provide outcomes of our interest. Then, the remaining 17 fulltext articles were assessed for eligibility. However, eight studies were excluded for the following reasons: four were unrelated with our topics; ${ }^{34} 37$ three did not provide outcomes of interest $;^{38-40}$ and one was an animal experiment. ${ }^{41}$ Finally, nine studies were included in this meta-analysis. ${ }^{12,14,23-26,42-44}$ The selection flowchart is shown in Figure 1.

\section{Characteristics of eligible studies}

The main characteristics of included studies are presented in Table 1. These studies were conducted between 1999 and 2014. The sample size of these studies ranged from 22 to 586 (total of 1,173 patients). All these trials were cohort studies. Among the nine studies, three were conducted in the US, three in People's Republic of China, one in Malaysia, one in Italy, and one in Canada. The median follow-up ranged from 24 months to 11 years. The quality of cohort studies was assessed by Newcastle-Ottawa Scale, and the scores ranged from 6 to 8 , which indicated that these studies had high quality (Table 1).

\section{Overall survival}

Eight studies reported the data of relationship between PTEN genetic mutation and the prognosis of patients with glioma. ${ }^{12,14,23-26,42,44}$ The aggregated results showed that glioma patients with PTEN genetic mutation had a significantly shorter OS than those without PTEN genetic mutation

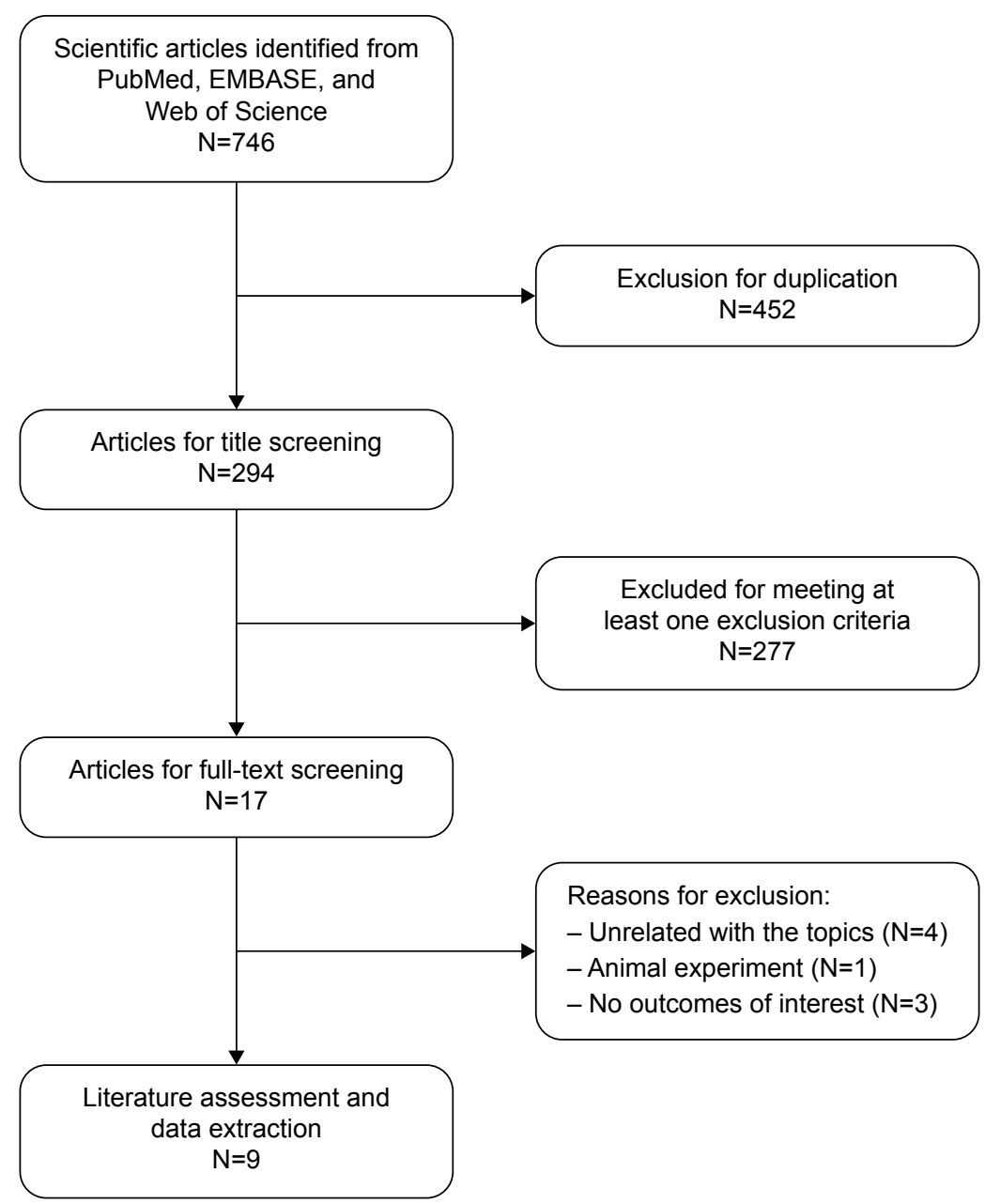

Figure I Search strategy and flowchart for the meta-analysis. 
Table I Characteristics of the studies included in the meta-analysis

\begin{tabular}{|c|c|c|c|c|c|c|c|c|}
\hline Study & $\mathbf{N}$ & $\begin{array}{l}\text { Year of } \\
\text { publication }\end{array}$ & Age (years) & $\begin{array}{l}\text { Malel } \\
\text { female }\end{array}$ & Tumor & Country & $\begin{array}{l}\text { Median } \\
\text { follow-up }\end{array}$ & NOS scale \\
\hline Smith et al ${ }^{12}$ & 174 & 2001 & $43(14-79)$ & $77 / 48$ & $\begin{array}{l}\text { Anaplastic astrocytoma/ } \\
\text { glioblastoma multiforme }\end{array}$ & USA & I04.7 months & 8 \\
\hline Carico et $\mathrm{al}^{14}$ & 155 & 2012 & NR & $100 / 55$ & Glioblastoma & USA & 3 years & 7 \\
\hline D'Urso et $\mathrm{al}^{24}$ & 59 & 2009 & 54.9 & $33 / 26$ & $\begin{array}{l}\text { Astrocytoma/ } \\
\text { oligoastrocytoma/ } \\
\text { anaplastic astrocytoma }\end{array}$ & Italy & 2 years & 7 \\
\hline James et $\mathrm{a}^{23}$ & 135 & 1999 & NR & $47 / 88$ & $\begin{array}{l}\text { Astrocytomas/ } \\
\text { oligoastrocytomas/ } \\
\text { oligodendrogliomas }\end{array}$ & USA & II years & 7 \\
\hline Abdullah et $\mathrm{a}^{25}$ & 37 & 2006 & $73 \%<40$ & NR & Astrocytoma & Malaysia & 3 years & 6 \\
\hline Yang et $\mathrm{al}^{26}$ & 22 & 2010 & $52(25-72)$ & $17 / 5$ & Gliomas & $\begin{array}{l}\text { People's Republic } \\
\text { of China }\end{array}$ & $8-10$ years & 7 \\
\hline Sasaki et $\mathrm{al}^{42}$ & 72 & 2001 & NR & NR & $\begin{array}{l}\text { Anaplastic } \\
\text { oligodendrogliomas }\end{array}$ & Canada & 10 years & 6 \\
\hline Wang et $\mathrm{a}^{43}$ & 88 & 2013 & $36(3-72)$ & $51 / 37$ & Glioma & $\begin{array}{l}\text { People's Republic } \\
\text { of China }\end{array}$ & 42 months & 8 \\
\hline Xu et $\mathrm{al}^{44}$ & 586 & 2014 & NR & NR & Glioma & $\begin{array}{l}\text { People's Republic } \\
\text { of China }\end{array}$ & I 25 months & 8 \\
\hline
\end{tabular}

Note: Data presented as median range unless otherwise stated.

Abbreviations: NOS, Newcastle-Ottawa Scale; NR, not reported.

$(\mathrm{HR}=2.23,95 \% \mathrm{CI}: 1.35,3.67 ; P=0.002)$ (Figure 2). The test for heterogeneity was significant $\left(P=0.000, I^{2}=86.5 \%\right)$. Subsequently, we conducted subgroup analysis to explore potential sources of heterogeneity. The results showed that the association between PTEN genetic mutation and poor prognostic of glioma was only observed among American patients (HR $=2.19,95 \%$ CI: $1.23,3.89 ; P=0.008)$, but not among Chinese patients (HR $=1.44,95 \% \mathrm{CI}$ : 0.29, 7.26; $P=0.657$ ).

Since the number of studies conducted in Malaysia, Italy, and Canada was only one, the subgroup analysis based

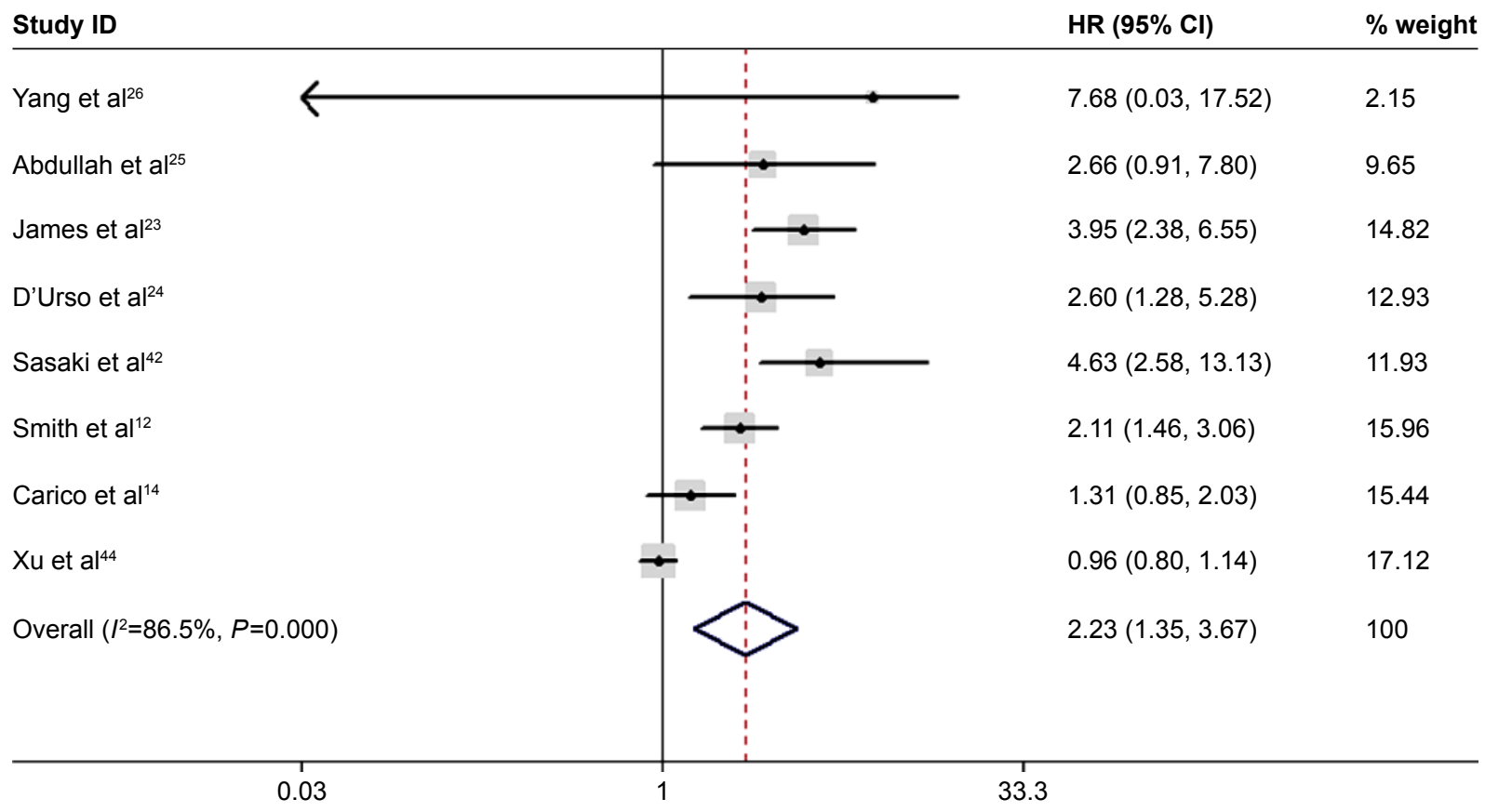

Figure 2 Forest plot showing the relationship between PTEN mutations and prognosis in patients with glioma. 


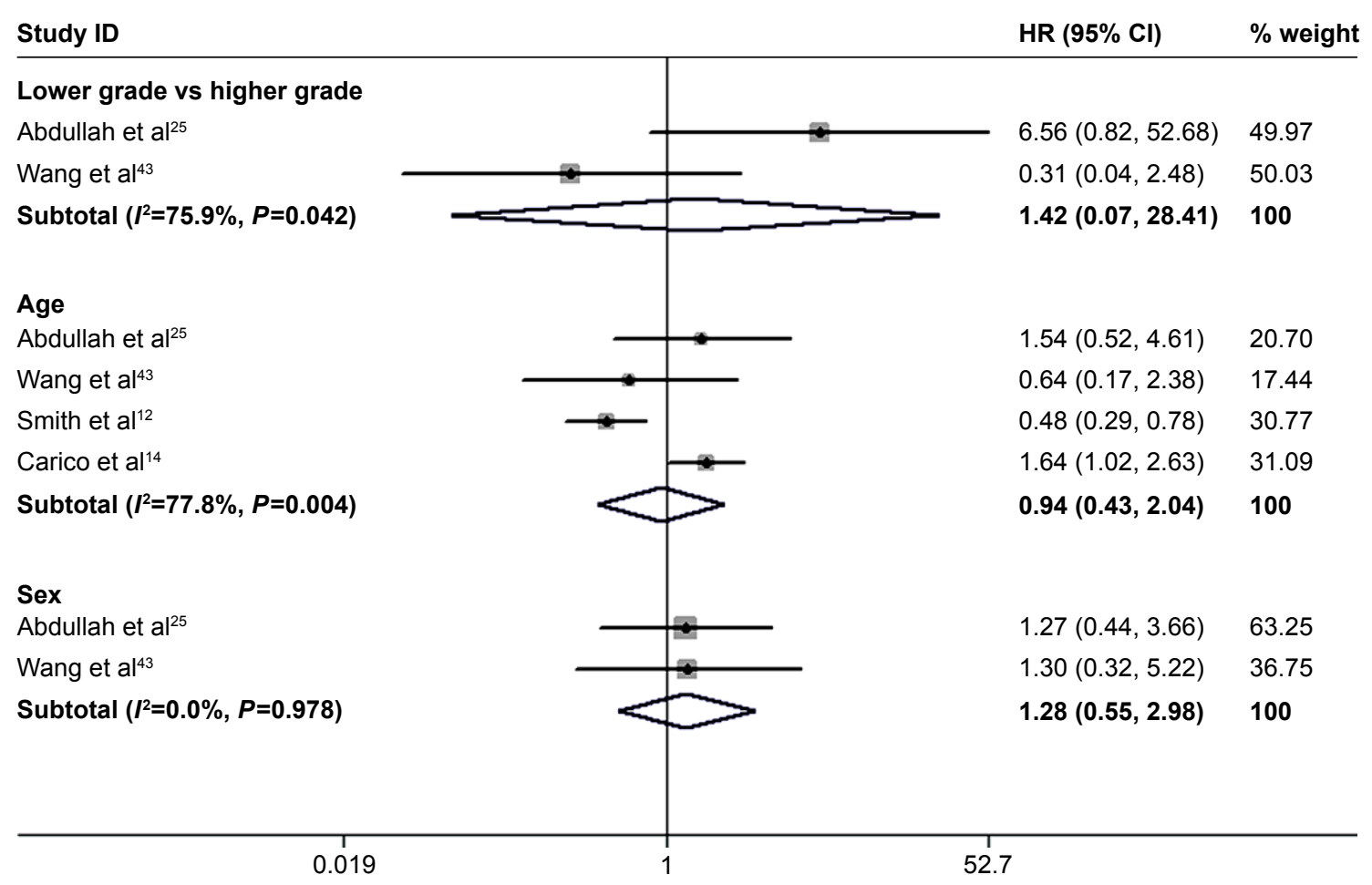

Figure 3 Forest plot showing the prognostic factors for the overall survival of glioma patients. Note: Weights are from random-effects analysis.

Abbreviations: $\mathrm{Cl}$, confidence interval; $\mathrm{HR}$, hazard ratio.

on these regions was not performed. The Begg and Egger tests revealed that no evidence of publication bias existed (for Begg's test, $Z=0.60, P=0.548$; for Egger's test, $t=0.90$, $P=0.411)$.

\section{Prognostic factors for the OS of glioma patients}

Four studies reported the data on prognostic factors for the OS of gliomapatients. ${ }^{12,14,25,43}$ The pooled results indicated that histopathological grade (HR $=1.42,95 \% \mathrm{CI}: 0.07,28.41$; $P=0.818)$, age $(\mathrm{HR}=0.94,95 \% \mathrm{CI}: 0.43,2.04 ; P=0.877)$, and sex $(\mathrm{HR}=1.28,95 \% \mathrm{CI}: 0.55,2.98 ; P=0.564)$ were not significant prognostic factors for the survival of patients with gliomas (Figure 3).

\section{Discussion}

The major aim of this meta-analysis was to investigate the relationship between PTEN mutations and prognosis in patients with glioma. This meta-analysis suggests that PTEN mutations are strongly associated with a shorter survival in patients with glioma. However, this relationship is only observed in American patients, but not in Chinese. Moreover, several factors, including histopathological grade, age, and sex, were not identified as prognostic factors for the survival of patients with gliomas.

The present study indicated that survival time of gliomas patients who had PTEN mutations was significantly shorter than these without PTEN mutations, which suggest that there is a strong correlation between PTEN status and patients' prognosis. According to these included studies, it is still controversial whether PTEN mutations are correlated to poor prognosis. Several studies have addressed whether PTEN mutations could be regarded as a potential candidate in predicting clinical outcome of glioma. These studies reported different types of glioma, four of which were glioblastoma ${ }^{14,24,26,44}$ and one was anaplastic oligodendroglioma. ${ }^{42}$ Their results showed that PTEN mutation was associated with poor prognosis of anaplastic oligodendroglioma patients. ${ }^{42}$ Whereas, for glioblastoma patients, the four studies reported inconsistent results. Two studies ${ }^{12,24}$ found this strong correlation while the remaining two $^{14,44}$ did not. Sasaki et al ${ }^{42}$ investigated 47 patients with anaplastic gliomas (seven treated with chemotherapy) and seven of them were detected with PTEN gene mutations. The median survival time for patients with or without PTEN mutations was 14.8 and 123.4 months, respectively, 
which indicated that PTEN mutations was associated with shorter survival in gliomas patients, even in chemosensitive cases. ${ }^{42}$ This demonstrated that PTEN mutations may be considered as one of the key prognostic factors for patients suffering from anaplastic oligodendrogliomas, and might be correlated to an aggressive tumor phenotype regardless of chemosensitivity. ${ }^{42}$ In another study conducted by Smith et al, ${ }^{12} 174$ patients with newly diagnosed gliomas were enrolled, of whom 63 were anaplastic astrocytoma and 111 were glioblastoma multiforme. PTEN gene alterations were detected in eleven out of 63 patients with anaplastic astrocytoma, and 37 out of 111 patients with glioblastoma multiforme. The median survival time of anaplastic astrocytoma patients with or without PTEN gene alteration was 4.4 and 34.4 months, respectively, whereas in glioblastoma patients with or without PTEN gene alteration, the median survival time was 11.7 and 11.2 months, respectively. This suggested that PTEN gene mutations may be regarded as a powerful prognostic factor for decreased survival time in patients with anaplastic astrocytoma.

However, two other studies ${ }^{25,26}$ identified no association between survival and mutation of PTEN gene in patients with gliomas. In the study conducted by Yang et al, ${ }^{26}$ a total of 22 patients suffering from gliomas were enrolled in that study. Among them, eleven cases of grade III and eleven cases of grade IV were defined as high-grade gliomas. The median survival time of patients with or without PTEN mutations was 67 and 99 weeks, respectively. ${ }^{26}$ However, the difference of the median survival time between the two groups did not reach the significance level. Consistent with this result, Abdullah et $\mathrm{al}^{25}$ also observed an insignificant result between PTEN mutations and survival time. In that study, 37 Malaysian glioma patients were analyzed, and seven of them showed PTEN mutations. Although the authors did not report the median survival time for each group, their result from multivariate Cox regression analysis showed that PTEN mutations did not have an impact on the survival time of patients with gliomas (HR $=2.66,95 \% \mathrm{CI}: 0.91,7.80 ; P=0.074)$.

In this meta-analysis, we found that several factors, including histopathological grade, age, and sex, were not identified as prognostic factors for the survival of patients with gliomas. These results were also observed in the study conducted by Abdullah et al, ${ }^{25}$ in which age (HR $=1.54$, 95\% CI: $0.52,4.61 ; P=0.450)$, sex (HR $=1.27,95 \% \mathrm{CI}: 0.44$, $3.66 ; P=0.661)$, and histopathological grade $(\mathrm{HR}=6.56$, $95 \%$ CI: $0.82,52.68 ; P=0.077)$ did not contribute to the survival outcome of the glioma patients. ${ }^{25}$ The authors thought that a significant association might be found if the sample size was larger than the sample in that study, since the PTEN mutations were only found in seven of 37 cases $(18.9 \%){ }^{25}$ And the high-grade tumors were found in 23 out of 37 cases (62.2\%). If the PTEN mutations were found in a higher proportion of high-grade tumors, the association between tumor grade and mutation would be significant.

\section{Limitations}

This study has several limitations. First, there was considerable heterogeneity among the studies, including differences in region, ethnicity, histopathological grade, and duration of follow-up. These factors have the potential to affect our results. Second, among the nine studies, some had a relative small sample size, which may result in an overestimation of the effect when compared with larger trials. Third, in this study, we found a strong correlation between PTEN mutations and poor prognosis, and this was mostly observed in anaplastic astrocytoma. However, when the tumor was glioblastoma multiforme, this relationship disappeared. Thus, we speculated that PTEN mutations could be used as an important prognostic factor for patients with anaplastic astrocytoma rather than glioblastoma multiforme. However, due to the limited studies reporting these data, this subgroup analysis was not performed. Fourth, some studies provided Kaplan-Meier curves rather than the HRs with 95\% CI for OS. In this case, we estimated the values of HRs with $95 \%$ CI from the Kaplan-Meier curves, which might lead to inaccurate data. Fifth, the data analysis of prognostic factors is based on only two studies, and the conclusion might not be representative and extensive. Thus, interpreting these results should be with caution. Last, although we searched three commonly used databases for eligible studies, we could not exclude the possibility that some non-English-language studies were missed. This may lead to bias in effect size.

\section{Conclusion}

This meta-analysis showed that PTEN genetic mutation is strongly correlated with poor prognosis in glioma patients. This may indicate that PTEN genetic mutation could be regarded as an important factor in the pathogenesis of glioma. However, this finding is derived from data in observational studies, potentially subject to selection bias, and hence well conducted, high-quality randomized controlled trials are warranted.

\section{Acknowledgments}

The authors thank Yiming Chen, Minghao Dong, Feng Liu, Luqian Feng, and Kaya Xu for their help in searching the 
information and organizing data. This study was funded by the United Fund of Guizhou Province Technology Hall in China (Qian Ke He LH Zi [2015] No. 7432) and the Doctoral Scientific Fund Project of Guizhou Medical University in China (YJ2014-19).

\section{Disclosure}

The authors report no conflicts of interest in this work.

\section{References}

1. Wrensch M, Minn Y, Chew T, Bondy M, Berger MS. Epidemiology of primary brain tumors: current concepts and review of the literature. Neuro Oncol. 2002;4(4):278-299.

2. Central brain tumor registry of the United States. Available from: http:// www.CBTRUS.org.

3. Ohgaki H, Dessen P, Jourde B, et al. Genetic pathways to glioblastoma: a population-based study. Cancer Res. 2004;64(19):6892-6899.

4. See SJ, Gilbert MR. Anaplastic astrocytoma: diagnosis, prognosis, and management. Semin Oncol. 2004;31(5):618-634.

5. Butowski NA, Sneed PK, Chang SM. Diagnosis and treatment of recurrent high-grade astrocytoma. J Clin Oncol. 2006;24(8):1273-1280.

6. Buckner JC. Factors influencing survival in high-grade gliomas. Semin Oncol. 2003;30(6 Suppl 19):10-14.

7. Tanase CP, Enciu AM, Mihai S, Neagu AI, Calenic B, Cruceru ML. Anticancer therapies in high grade gliomas. Curr Proteomics. 2013;10(3): 246-260.

8. Li J, Yen C, Liaw D, et al. PTEN, a putative protein tyrosine phosphatase gene mutated in human brain, breast, and prostate cancer. Science. 1997;275(5308):1943-1947.

9. Ming M, He YY. PTEN in DNA damage repair. Cancer Lett. 2012; 319(2):125-129.

10. Ortega-Molina A, Serrano M. PTEN in cancer, metabolism, and aging. Trends Endocrinol Metab. 2013;24(4):184-189.

11. Koul D. PTEN signaling pathways in glioblastoma. Cancer Biol Ther. 2008;7(9):1321-1325.

12. Smith JS, Tachibana I, Passe SM, et al. PTEN mutation, EGFR amplification, and outcome in patients with anaplastic astrocytoma and glioblastoma multiforme. J Natl Cancer Inst. 2001;93(16): 1246-1256.

13. Srividya MR, Thota B, Shailaja BC, et al. Homozygous 10q23/PTEN deletion and its impact on outcome in glioblastoma: a prospective translational study on a uniformly treated cohort of adult patients. Neuropathology. 2011;31(4):376-383.

14. Carico C, Nuno M, Mukherjee D, et al. Loss of PTEN is not associated with poor survival in newly diagnosed glioblastoma patients of the temozolomide era. PLoS One. 2012;7(3):e33684.

15. Aberle H, Bauer A, Stappert J, Kispert A, Kemler R. Beta-catenin is a target for the ubiquitin-proteasome pathway. EMBO J. 1997;16(13): 3797-3804.

16. Sun H, Lesche R, Li DM, et al. PTEN modulates cell cycle progression and cell survival by regulating phosphatidylinositol 3,4,5,-trisphosphate and Akt/protein kinase B signaling pathway. Proc Natl Acad Sci US A. 1999;96(11):6199-6204.

17. Chenn A, Walsh CA. Regulation of cerebral cortical size by control of cell cycle exit in neural precursors. Science. 2002;297(5580): 365-369.

18. Fraser MM, Zhu X, Kwon CH, Uhlmann EJ, Gutmann DH, Baker SJ. Pten loss causes hypertrophy and increased proliferation of astrocytes in vivo. Cancer Res. 2004;64(21):7773-7779.

19. Chen Y, Huang WC, Sejourne J, Clipperton-Allen AE, Page DT. Pten mutations alter brain growth trajectory and allocation of cell types through elevated beta-catenin signaling. $J$ Neurosci. 2015;35(28):10252-10267.
20. Tilot AK, Gaugler MK, Yu Q, et al. Germline disruption of Pten localization causes enhanced sex-dependent social motivation and increased glial production. Hum Mol Genet. 2014;23(12):3212-3227.

21. Rasheed BK, Stenzel TT, McLendon RE, et al. PTEN gene mutations are seen in high-grade but not in low-grade gliomas. Cancer Res. 1997; 57(19):4187-4190.

22. Kitange GJ, Templeton KL, Jenkins RB. Recent advances in the molecular genetics of primary gliomas. Curr Opin Oncol. 2003;15(3):197-203.

23. James CD, Galanis E, Frederick L, et al. Tumor suppressor gene alterations in malignant gliomas: histopathological associations and prognostic evaluation. Int J Oncol. 1999;15(3):547-553.

24. D'Urso OF, D'Urso PI, Marsigliante S, et al. Correlative analysis of gene expression profile and prognosis in patients with gliomatosis cerebri. Cancer. 2009;115(16):3749-3757.

25. Abdullah JM, Farizan A, Asmarina K, et al. Association of loss of heterozygosity and PTEN gene abnormalities with paraclinical, clinical modalities and survival time of glioma patients in Malaysia. Asian $J$ Surg. 2006;29(4):274-282.

26. Yang Y, Shao N, Luo G, et al. Mutations of PTEN gene in gliomas correlate to tumor differentiation and short-term survival rate. Anticancer Res. 2010;30(3):981-985.

27. Wells G, Shea B, Connell D, et al. The Newcastle-Ottawa Scale (NOS) for assessing the quality of nonrandomized studies in meta-analyses. In: Third Symposium on Systematic Reviews: Beyond the Basics; July 3-5, 2000; Oxford.

28. Higgins JP, Thompson SG, Deeks JJ, Altman DG. Measuring inconsistency in meta-analyses. BMJ. 2003;327(7414):557-560.

29. DerSimonian R, Laird N. Meta-analysis in clinical trials. Control Clin Trials. 1986;7(3):177-188.

30. Mantel N, Haenszel W. Statistical aspects of the analysis of data from retrospective studies of disease. J Natl Cancer Inst. 1959;22(4): 719-748.

31. Tierney JF, Stewart LA, Ghersi D, Burdett S, Sydes MR. Practical methods for incorporating summary time-to-event data into meta-analysis. Trials. 2007;8:16.

32. Begg CB, Mazumdar M. Operating characteristics of a rank correlation test for publication bias. Biometrics. 1994;50(4):1088-1101.

33. Egger M, Davey Smith G, Schneider M, Minder C. Bias in meta-analysis detected by a simple, graphical test. BMJ. 1997;315(7109):629-634.

34. Wang $\mathrm{Y}$, Fan $\mathrm{X}$, Zhang $\mathrm{C}$, et al. Identifying radiographic specificity for phosphatase and tensin homolog and epidermal growth factor receptor changes: a quantitative analysis of glioblastomas. Neuroradiology. 2014;56(12):1113-1120.

35. Saha R, Chatterjee U, Mandal S, Saha K, Chatterjee S, Ghosh SN. Expression of phosphatase and tensin homolog, epidermal growth factor receptor, and Ki-67 in astrocytoma: A prospective study in a tertiary care hospital. Indian J Med Paediatr Oncol. 2014;35(2):149-155.

36. Lv S, Teugels E, Sadones J, et al. Correlation of EGFR, IDH1 and PTEN status with the outcome of patients with recurrent glioblastoma treated in a phase II clinical trial with the EGFR-blocking monoclonal antibody cetuximab. Int J Oncol. 2012;41(3):1029-1035.

37. Chan CM, Mitchell AL, Shorr AF. Etomidate is associated with mortality and adrenal insufficiency in sepsis: a meta-analysis. Crit Care Med. 2012;40(11):2945-2953.

38. Prados MD, Chang SM, Butowski N, et al. Phase II study of erlotinib plus temozolomide during and after radiation therapy in patients with newly diagnosed glioblastoma multiforme or gliosarcoma. JClin Oncol. 2009;27(4):579-584.

39. Karsy M, Neil JA, Guan J, Mahan MA, Colman H, Jensen RL. A practical review of prognostic correlations of molecular biomarkers in glioblastoma. Neurosurg Focus. 2015;38(3):E4.

40. Kraus JA, Glesmann N, Beck M, et al. Molecular analysis of the PTEN, TP53 and CDKN2A tumor suppressor genes in long-term survivors of glioblastoma multiforme. J Neurooncol. 2000;48(2):89-94.

41. Inaba N, Kimura M, Fujioka K, et al. The effect of PTEN on proliferation and drug-, and radiosensitivity in malignant glioma cells. Anticancer Res. 2011;31(5):1653-1658. 
42. Sasaki H, Zlatescu MC, Betensky RA, Ino Y, Cairncross JG, Louis DN. PTEN is a target of chromosome $10 \mathrm{q}$ loss in anaplastic oligodendrogliomas and PTEN alterations are associated with poor prognosis. $\mathrm{Am}$ J Pathol. 2001;159(1):359-367.

43. Wang C, Fang M, Zhang M, et al. The positive correlation between DJ-1 and beta-catenin expression shows prognostic value for patients with glioma. Neuropathology. 2013;33(6):628-636.
44. Xu J, Li Z, Wang J, Chen H, Fang JY. Combined PTEN mutation and protein expression associate with overall and disease-free survival of glioblastoma patients. Transl Oncol. 2014;7(2):196-205.e1.

\section{Publish your work in this journal}

OncoTargets and Therapy is an international, peer-reviewed, open access journal focusing on the pathological basis of all cancers, potential targets for therapy and treatment protocols employed to improve the management of cancer patients. The journal also focuses on the impact of management programs and new therapeutic agents and protocols on

\section{Dovepress}

patient perspectives such as quality of life, adherence and satisfaction. The manuscript management system is completely online and includes a very quick and fair peer-review system, which is all easy to use. Visit http://www.dovepress.com/testimonials.php to read real quotes from published authors. 